\title{
Frações proteicas do capim-mombaça submetido a doses de nitrogênio em duas alturas de corte
}

[Proteins fractions of mombaça grass submitted to nitrogen doses at two cutting heights]

\author{
A.G. Silva, A.F.S. França*, E.S. Miyagi, S.Q.S. Mello, J.L. Ferreira, E.R. Carvalho \\ Escola de Veterinária - UFG \\ Caixa Postal: 131 \\ 74001-970 - Goiânia, GO
}

\begin{abstract}
RESUMO
Foram caracterizadas e identificadas as frações proteicas constituintes do capim-mombaça submetido a quatro doses de nitrogênio $\left(0,100,300\right.$ e $\left.500 \mathrm{~kg} \cdot \mathrm{ha}^{-1}\right)$ em duas alturas de corte no período chuvoso e no seco. Utilizou-se delineamento experimental em blocos casualizados, em esquema fatorial $4 \mathrm{x} 2$, com quatro repetições. Os teores de proteína bruta $(\mathrm{PB})$ e das frações $\mathrm{A}, \mathrm{B}_{1}, \mathrm{~B}_{2}, \mathrm{~B}_{3}$ e $\mathrm{C}$ da proteína do capimmombaça, cortado a 0,20 e 0,40m da superfície do solo foram avaliados pelo Cornell Net Carbohydrate and Protein System. Em relação ao teor de $\mathrm{PB}$, ocorreu diferença significativa $(\mathrm{P}<0,05)$ quanto às doses aplicadas. Observou-se aumento de PB em função da elevação das doses de N, principalmente no período chuvoso apresentando valores médios em torno de $10 \%$. Ocorreu diferença nas frações de PB em função da estação e da altura de corte. As frações $\mathrm{B}_{1} \mathrm{e} \mathrm{C}$ não diferiram quanto à dose de $\mathrm{N}$ e altura de corte. As frações $\mathrm{A}+\mathrm{B}_{1}$ foram maiores no período seco, nas duas alturas residuais $(\mathrm{P}<0,05)$. A dose de nitrogênio e a altura do corte influenciaram na composição das frações proteicas.
\end{abstract}

Palavras-chave: capim-mombaça, Panicum maximum, adubação nitrogenada, composto nitrogenado

\begin{abstract}
The protein fractions of mombaça grass submitted to four nitrogen doses $\left(0,100,300\right.$, and $\left.500 \mathrm{~kg} . \mathrm{ha}^{-1}\right)$ at two cutting heights in dry and rainy periods were characterized and identified. A completely randomized block design, in $2 \times 4$ factorial scheme with four repetitions, was used. The crude protein (CP) and $A, B_{1}$, $B_{2}, B_{3}$, and $C$ protein fractions of mombaça grass cut at 0.20 and $0.40 \mathrm{~m}$ were evaluated by the Cornell Net Carbohydrate and Protein System. There was significant difference $(P<0.05)$ for $C P$ according to the nitrogen $(N)$ dose. The $C P$ percentage increased as the $N$ dose increased, in rainy period, averaging around $10 \%$. There was difference for $C P$ in function of season and cutting heights. The B1 and $C$ fractions did not significantly differ concerning $N$ dose and cutting heights. The $A+B 1$ fractions were higher in the dry period in both heights $(P<0.05)$. The $N$ dose and cutting heights influenced in protein fractions composition.
\end{abstract}

Keywords: mombaça grass, Panicum maximum, nitrogen composites, nitrogen fertilization

\section{INTRODUÇ̃̃o}

A atividade pecuária é bastante difundida por todo o país, com destaque para alguns polos produtivos de carne, entre eles a região CentroOeste. Em virtude da grande exploração de áreas de Cerrado, é cada vez mais frequente a utilização de pastagens cultivadas visando alcançar melhores índices produtivos. O capimmombaça (Panicum maximum cv Mombaça) é uma planta ereta e cespitosa, com altura média de $1,65 \mathrm{~m}$ e alta porcentagem de folhas (cerca de $80 \%$ ), e somente $10 \%$ da sua produção ocorre na estação seca (Carnevalli, 2003). A adubação

Recebido em 22 de janeiro de 2009

Aceito em 29 de setembro de 2009

*Autor para correspondência (corresponding author)

E-mail: aldi@vet.ufg.br 
nitrogenada é extremamente importante para a intensificação do uso das pastagens nas regiões tropicais, desde que outros nutrientes não sejam limitantes, proporcionando elevada produtividade das forrageiras. $O$ nitrogênio é componente essencial de aminoácidos e proteínas, de ácidos nucleicos, de hormônios e clorofila, dentre os compostos orgânicos essenciais à vida das plantas, além de ser um dos nutrientes mais extraídos pelas plantas (Lavres, 2001). As plantas forrageiras sofrem alterações morfológicas importantes com o pastejo ou o corte. Assim, a determinação da altura ou a intensidade de pastejo adequada é um pontochave para a perenidade das gramíneas.

Níveis de resíduos pós-pastejo muito baixos podem proporcionar menor desempenho animal, pois esses apresentam maior dificuldade de apreensão da planta, reduzindo o consumo de forragem (Burlison et al., 1991), além de ingerirem maior proporção de colmo, o qual, geralmente, apresenta menores teores de PB, baixa digestibilidade e maiores teores de FDN e FDA. No entanto, e apesar desses entraves, Santos et al. (1999) relataram que as plantas manejadas com menores resíduos podem apresentar melhor qualidade nutricional, devido à maior renovação de tecidos.

Novos sistemas e metodologias de avaliação de alimentos para ruminantes estão sendo utilizados com intuito de maximizar o uso dos nutrientes pelos animais. O Cornell Net Carbohydrate and Protein System é um sistema que considera a dinâmica da fermentação ruminal e a perda potencial de nitrogênio, como amônia, na avaliação dos alimentos (Sniffen et al., 1992) e tem por objetivo adequar a digestão ruminal dos carboidratos e das proteínas, visando maximizar a produção microbiana, a redução das perdas do nitrogênio pelo animal e estimar o escape ruminal de nutrientes (Balsalobre et al., 2003).

Segundo Van Soest (1994), os constituintes químicos e as taxas de degradação dos alimentos produzidos em condições tropicais diferem grandemente daqueles produzidos em regiões de clima temperado. Diante dessa situação, é importante obter dados sobre as forrageiras tropicais, visto que tais informações ainda são escassas. Nesse sentido, o fracionamento da proteína de gramíneas do gênero Panicum permitirá uma melhor caracterização da composição desses nutrientes.

Este experimento teve o objetivo de caracterizar e identificar as frações proteicas do capimmombaça submetido a doses de nitrogênio, em duas alturas de corte, nos períodos chuvoso e seco, ao longo de um ano, nas condições do município de Goiânia - GO.

\section{MATERIAL E MÉTODOS}

O experimento foi realizado na Fazenda Modelo da Escola de Veterinária da Universidade Federal de Goiás, em Goiânia, GO. Esta região situa-se a $16^{\circ} 41^{\prime \prime}$ de latitude S, $49^{\circ} 17^{\prime}$ de longitude $\mathrm{W}$, com altitude de $741 \mathrm{~m}$. O clima predominante, segundo a classificação de Köppen, é do tipo $\mathrm{AW}$ (quente e semiúmido, com estação seca bem definida dos meses de maio a outubro). O mês de junho apresenta a menor média de temperatura mínima do ar $\left(14^{\circ} \mathrm{C}\right)$, já a maior média, no mês de setembro, é de $31,3^{\circ} \mathrm{C}$. A temperatura média anual é de $23,2^{\circ} \mathrm{C}$, com média numérica anual de $17,9^{\circ} \mathrm{C}$, a precipitação média anual é de $1759 \mathrm{~mm}$ e a umidade do ar média anual é de $71 \%$, com o menor índice no mês de agosto (Brasil, 1992). Os dados meteorológicos relativos ao período experimental encontram-se na Tab. 1.

O solo da área experimental é classificado em latossolo vermelho distrófico e, para fins de sua caracterização química, foram coletadas amostras na profundidade de $0,20 \mathrm{~m}$. Na Tab. 2, são apresentados os dados dos atributos químicos do solo da área experimental antes da instalação do experimento.

No preparo do solo da área experimental, foi utilizado o arado de disco, seguido por duas gradagens. Em 11/09/2003, procedeu-se à semeadura a lanço do capim-mombaça, empregando-se uma taxa de semeadura de $1,6 \mathrm{~kg}$ $\mathrm{ha}^{-1}$ de sementes puras e viáveis. Após o estabelecimento da pastagem, efetuou-se o corte de uniformização em 14/11/2003, sendo, então, alocadas 32 parcelas de $16 \mathrm{~m}^{2}(4 \mathrm{~m} \times 4 \mathrm{~m})$, espaçadas de um metro, ocupando área total de $512 \mathrm{~m}^{2}$. Em seguida, retiraram-se os resíduos e aplicou-se a adubação potássica $60 \mathrm{~kg} \mathrm{~K}_{2} \mathrm{O} \mathrm{ha}{ }^{-1}$ (cloreto de potássio). 
Tabela 1. Variáveis climáticas observadas durante o período experimental

\begin{tabular}{lccccc}
\multicolumn{2}{c}{ Meses/ano } & \multirow{2}{*}{ Insolação (horas) } & Precipitação pluvial $(\mathrm{mm})$ & \multicolumn{3}{c}{ Temperatura média do ar $\left({ }^{0} \mathrm{C}\right)$} \\
\cline { 4 - 6 } & & & Máxima & Mínima & Média \\
\hline Novembro/2005 & 135,1 & 297,0 & 30,2 & 18,3 & 24,5 \\
Dezembro/2005 & 120,7 & 375,7 & 29,1 & 18,8 & 23,0 \\
Janeiro/2006 & 193,7 & 173,4 & 30,9 & 18,2 & 23,8 \\
Fevereiro/2006 & 127,5 & 230,2 & 30,3 & 18,9 & 23,4 \\
Março/2006 & 151,0 & 326,0 & 30,3 & 19,0 & 23,4 \\
Abril/2006 & 195,1 & 159,8 & 30,6 & 17,5 & 22,8 \\
Maio/2006 & 241,7 & 22 & 29,6 & 11,9 & 19,6 \\
Junho/2006 & 254,1 & 0,0 & 29,2 & 10,8 & 19,0 \\
Julho/2006 & 248,9 & 0,0 & 30,0 & 9,9 & 19,3 \\
Agosto/2006 & 268,2 & 1,6 & 32,9 & 12,5 & 22,1 \\
Setembro/2006 & 200,8 & 45,8 & 32,6 & 15,4 & 23,3 \\
Outubro/2006 & 140,8 & 268,6 & 30,3 & 18,5 & 23,5 \\
\hline
\end{tabular}

Fonte: Estação Evaporimétrica de primeira classe, Escola de Agronomia - UFG.

Tabela 2. Atributos químicos do solo da área experimental

\begin{tabular}{|c|c|c|c|c|c|c|c|c|c|}
\hline $\mathrm{Ca}$ & $\mathrm{Mg}$ & CTC & $\mathrm{Al}$ & $\mathrm{H}$ & $\mathrm{P}(\mathrm{Mel})$ & K & $\mathrm{pH}$ & V & M.O. \\
\hline & & $\overline{\mathrm{mol}_{\mathrm{c}} \cdot \mathrm{d}}$ & & & \multicolumn{2}{|c|}{ mg.dm ${ }^{3}$} & $\mathrm{CaCl}_{2}$ & $\%$ & $\mathrm{~g} / \mathrm{kg}$ \\
\hline 4,0 & 2,0 & 9,4 & 0 & 1,9 & 17,5 & 114,0 & 5,6 & 67,0 & 39 \\
\hline
\end{tabular}

Os tratamentos foram constituídos por quatro doses de nitrogênio zero, 100,300 e $500 \mathrm{~kg} \mathrm{ha}^{-1}$, tendo o sulfato de amônio como fonte, e duas alturas residuais 0,20 e $0,40 \mathrm{~m}$, com quatro repetições. O delineamento utilizado foi $\mathrm{o}$ de blocos ao acaso com parcelas subdivididas, em esquema fatorial $4 \times 2$.

A adubação nitrogenada foi parcelada em função da época do ano. Dessa forma, $80 \%$ da dose foram aplicados no período chuvoso, quando foram feitos cortes a cada 30 dias, e $20 \%$ no período de seca, com cortes a cada 60 dias. As avaliações iniciaram-se em dezembro/2005 e estenderam-se até novembro/2006. No período chuvoso, os cortes foram realizados em $10 / 12 / 2005,14 / 01 / 2006,18 / 02 / 2006,18 / 03 / 2006$ e 26/04/2006; no período seco, em 01/07/2006, $02 / 09 / 2006$ e $04 / 11 / 2006$.

Os cortes manuais e o rebaixamento da parcela seguiram a rotina para experimentos dessa natureza. A adubação potássica de manutenção foi realizada com a aplicação de $15 \mathrm{~kg} \mathrm{ha}^{-1}$ de $\mathrm{K}_{2} \mathrm{O}$ por tonelada de massa seca retirada da área, seguindo a recomendação de Monteiro (1995).

Do material coletado foi retirada uma subamostra de, aproximadamente, $500 \mathrm{~g}$ para a determinação da matéria seca parcial. As amostras foram, então, moídas conforme se recomenda para esse tipo de experimento. Para as determinações propostas, as amostras foram homogeneizadas por período segundo os tratamentos, totalizando cinco amostragens no período chuvoso e três no período seco, formando um pool visando às análises de matéria seca (MS) e proteína bruta (PB) conforme metodologia descrita por Silva e Queiroz (2002). As determinações de nitrogênio não proteico (NNP), nitrogênio insolúvel em detergente neutro (NIDN) e em detergente ácido (NIDA) foram executadas segundo a metodologia descrita por Licitra et al. (1996), e o nitrogênio solúvel (NS) de acordo com Krishnamoorthy et al. (1982), realizadas em Macro Kjedal. A fibra em detergente neutro e a fibra em detergente ácido utilizadas para a determinação do teor de nitrogênio foram analisadas em equipamento convencional de fibra, não se utilizando o sulfito de sódio.

As frações de proteína foram calculadas pelo sistema CNCPS (Sniffen et al., 1992). A proteína foi analisada e calculada para as cinco frações, $\mathrm{A}, \mathrm{B}_{1}, \mathrm{~B}_{2}, \mathrm{~B}_{3}$ e $\mathrm{C}$ em porcentagem da $\mathrm{PB}$.

A fração A, constituída de compostos (NNP), foi determinada pela diferença entre o $\mathrm{N}$ total e o $\mathrm{N}$ insolúvel em ácido tricloracético (TCA) conforme a seguinte fórmula: $\mathrm{A}(\% \mathrm{Nt})=\mathrm{Nt}-\mathrm{N}_{1}$ 
/ Nt x 100, em que: $\mathrm{Nt}=$ nitrogênio total da amostra e $\mathrm{N}_{1}=$ teor de nitrogênio insolúvel em ácido tricloracético . A fração $B_{1}$ referente às proteínas solúveis, rapidamente degrada do rúmen, foi obtida pela diferença entre o nitrogênio solúvel em tampão borato fosfato (TBF) menos o NNP, calculada pela seguinte fórmula: $\mathrm{B}_{1}(\% \mathrm{Nt})=\mathrm{N}_{1}-\mathrm{N}_{2} / \mathrm{Nt}$ x 100 , em que: $\mathrm{N}_{2}=$ nitrogênio insolúvel em tampão borato fosfato. As frações $B_{2}$ e $B_{3}$, constituídas pelas proteínas insolúveis com taxa de degradação intermediária e lenta no rúmen, foram determinadas pela diferença entre a fração insolúvel em TBF e a fração da NIDN, a NIDN menos a NIDA, respectivamente. $\mathrm{O}$ valor de $\mathrm{B}_{2}$ é dado por: $\mathrm{B}_{2}(\% \mathrm{Nt})=\mathrm{N}_{2}-\mathrm{NIDN} / \mathrm{Nt} \times 100$ e a fração $\mathrm{B}_{3}(\% \mathrm{Nt})=\mathrm{NIDN}-\mathrm{NIDA} / \mathrm{Nt} \times 100$. A fração $\mathrm{C}$, constituída de proteínas insolúveis e indigeríveis no rúmen e intestinos, foi determinada pelo conteúdo de nitrogênio residual da amostra após ser tratada com detergente ácido (NIDA) e expressa em percentagem do $\mathrm{Nt}$ da amostra.

Para a análise de variância, usou-se o programa PROC GLM do sistema SAS/2001, as médias foram comparadas pelo teste de $\mathrm{t}$ com significância de $5 \%$.

\section{RESULTADOS E DISCUSSÃO}

Em relação ao teor de $\mathrm{PB}$, em ambos os períodos avaliados, houve diferença $(\mathrm{P}<0,05)$ entre as doses aplicadas. Observaram-se acréscimos em função da elevação das doses de N (Fig. 1).
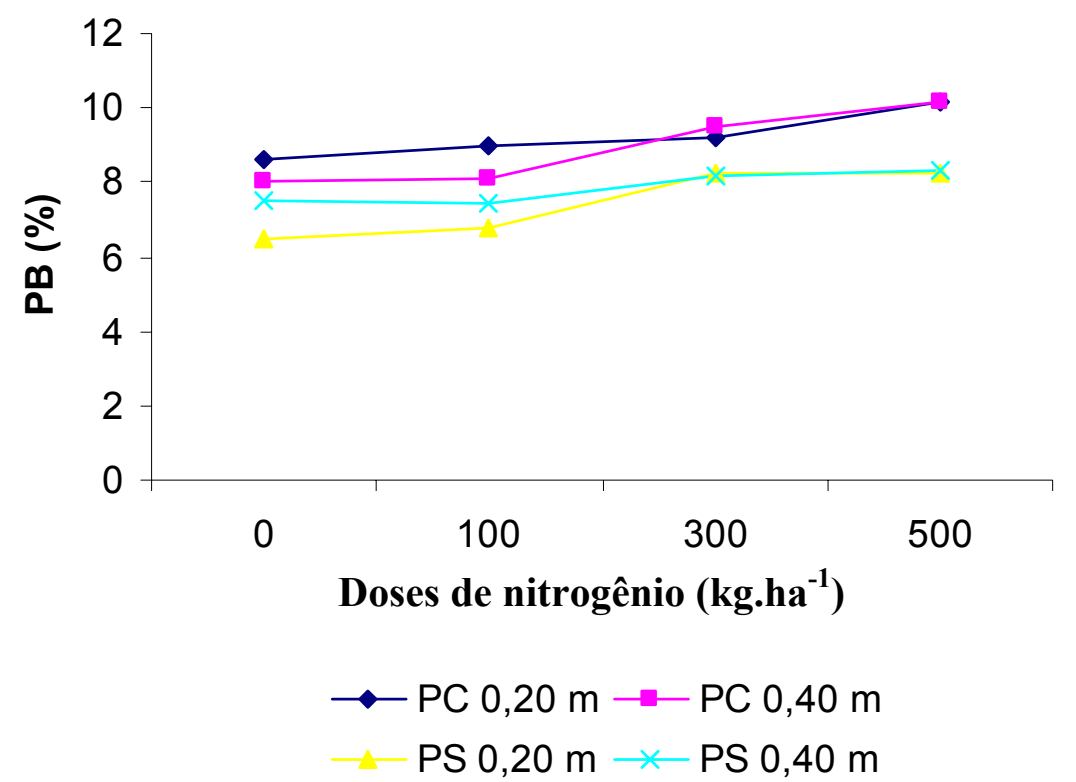

Figura 1. Teor de proteína bruta (PB) do capim-mombaça submetido a diferentes doses de nitrogênio e alturas de corte no período chuvoso (PC) e seco (PS).

Balsalobre et al. (2003), em experimento com capim-tanzânia irrigado, sob três níveis de resíduo pós-pastejo, relataram tendência de aumento de PB ao longo dos ciclos de pastejo. Os menores valores de $\mathrm{PB}$ encontrados por esses autores foram em torno de $11,5 \%$, obtidos nos primeiros cinco ciclos de pastejo, e o maior foi no último pastejo, com média de 14,6\%.

Resultados semelhantes foram encontrados nas duas alturas residuais. Os maiores teores foram determinados no período chuvoso, por ocasião da aplicação da dose equivalente a $500 \mathrm{~kg} \cdot \mathrm{ha}^{-1}$ de $\mathrm{N}$, com valores médios em torno de $10 \%$. Valores mais altos foram encontrados por Ribeiro et al. (2001), em experimento com feno de capimtifton 85 , obtido de plantas colhidas entre 28 a 56 dias, adubadas com $75 \mathrm{~kg} \cdot \mathrm{ha}^{-1}$ de N/corte. Como os teores proteicos dos fenos decresceram com a idade de rebrota, os valores obtidos foram de 17,$6 ; 16,5 ; 15,1$ e $12,6 \%$ para $28,35,42$ e 56 dias de rebrota, respectivamente. 
Neste trabalho, os valores de proteína bruta nas doses aplicadas de: $0,100,300$ e $500 \mathrm{~kg} \mathrm{ha}^{-1}$ de N foram: 8,$7 ; 8,8 ; 9,4$ e $10,6 \%$ na altura residual de $0,20 \mathrm{~m}$; e 7,$5 ; 8,4 ; 9,1$ e $10,2 \%$ na altura residual de $0,40 \mathrm{~m}$, no período chuvoso. No período seco, os teores foram: 6,$47 ; 6,77 ; 8,22 ; 8,23 \%$ e de 7,$50 ; 7,43 ; 8,14$ e $8,34 \%$ para as duas alturas residuais, respectivamente. Ao avaliarem o capim-mombaça, submetido a cinco lâminas de irrigação e adubado com quatro doses de $\mathrm{N}$, Ruggiero et al. (2006) observaram acréscimos nos teores de $\mathrm{PB}$ em função das doses de $\mathrm{N}$ aplicadas, com valores mais altos no período chuvoso, com as maiores médias para o mês de outubro, 12,$5 ; 13,7 ; 15,4$ e $17,0 \%$, e menores no mês de julho, 7,$3 ; 8,1 ; 8,5$ e $9,1 \%$, para as doses de $100,200,300$ e $400 \mathrm{~kg} \cdot \mathrm{ha}^{-1}$ de N/ano, respectivamente. Os valores, determinados no período chuvoso podem estar associados às melhores condições edafoclimáticas regionais e à alta relação folha/colmo da planta forrageira. Cândido et al. (2005), em trabalho realizado em pastagem de capim-mombaça sob lotação intermitente, relataram que o teor de proteína bruta variou em função da duração dos períodos de descanso e dos dias de pastejo. O ponto de mínimo correspondeu à idade de 44 dias. Para este ponto de mínimo, as respostas críticas relativas ao primeiro, terceiro e quinto dias de pastejo foram de 9,$3 ; 8,5$ e $6,3 \%$ PB, respectivamente.

Apesar de os valores de PB mais baixos, menor que $7 \%$, observados no período seco para as doses de 0 e $100 \mathrm{~kg} \mathrm{ha}^{-1}$ de $\mathrm{N}$, os teores de PB determinados neste experimento são semelhantes aos encontrados na literatura. Isto confirma os resultados observados por Brâncio et al. (2002), que avaliaram três cultivares de Panicum sob pastejo, dentre esses o cv tanzânia, submetido a uma adubação nitrogenada adicional. Segundo os autores, essa adubação pode ser compensatória, uma vez que a não adubação em março resultou em teores próximos ou abaixo de 7\%, considerado crítico por Van Soest (1994). Abaixo deste valor, ocorreria restrição ao consumo voluntário, por reduzir a atividade de microrganismos no rúmen e, assim, a taxa de digestão da celulose e o tempo de retenção da forragem no rúmen.

Nas Tab. 3 e 4, encontram-se as frações de proteína $\left(\mathrm{A}, \mathrm{B}_{1}, \mathrm{~B}_{2}, \mathrm{~B}_{3}\right.$ e $\left.\mathrm{C}\right)$ referentes ao período chuvoso e seco, respectivamente. Houve diferença entre as frações nitrogenadas quanto à dose e entre as alturas de corte em relação aos períodos estudados $(\mathrm{P}<0,05)$.

Tabela 3. Frações dos compostos nitrogenados do capim-mombaça (\%MS), obtidas pelo sistema CNCPS, durante o período chuvoso

\begin{tabular}{|c|c|c|c|c|}
\hline \multirow{2}{*}{$\begin{array}{l}\text { Altura } \\
\text { (m) }\end{array}$} & \multicolumn{4}{|c|}{ Dose de nitrogênio $\left(\mathrm{kg} \mathrm{ha}^{-1}\right)$} \\
\hline & 0 & 100 & 300 & 500 \\
\hline & & Fração A & & \\
\hline 0,20 & $35,25 \mathrm{Aa}$ & $34,71 \mathrm{Aa}$ & $30,62 \mathrm{Bb}$ & $26,54 \mathrm{Cb}$ \\
\hline 0,40 & $32,80 \mathrm{Cb}$ & $33,63 \mathrm{Bb}$ & $35,22 \mathrm{Aa}$ & $28,69 \mathrm{Da}$ \\
\hline & & Fração $B_{1}$ & & \\
\hline 0,20 & $2,56 \mathrm{Ba}$ & $4,10 \mathrm{Aa}$ & $4,04 \mathrm{Aa}$ & $3,77 \mathrm{Aa}$ \\
\hline 0,40 & $1,58 \mathrm{Ab}$ & $1,28 \mathrm{Ab}$ & $1,50 \mathrm{Ab}$ & $1,26 \mathrm{Ab}$ \\
\hline & & Fração $B_{2}$ & & \\
\hline 0,20 & $19,94 \mathrm{Aa}$ & $20,52 \mathrm{Ab}$ & $17,35 \mathrm{Ba}$ & $17,49 \mathrm{Ba}$ \\
\hline 0,40 & $20,36 \mathrm{Ba}$ & $24,66 \mathrm{Aa}$ & $17,07 \mathrm{Ca}$ & $14,13 \mathrm{Db}$ \\
\hline & & Fração $B_{3}$ & & \\
\hline 0,20 & $33,71 \mathrm{Cb}$ & $32,23 \mathrm{Da}$ & $38,52 \mathrm{Ba}$ & $41,69 \mathrm{Ab}$ \\
\hline 0,40 & $35,87 \mathrm{Ba}$ & $30,82 \mathrm{Cb}$ & $35,94 \mathrm{Bb}$ & $44,46 \mathrm{Aa}$ \\
\hline & & Fração C & & \\
\hline 0,20 & $8,51 \mathrm{Cb}$ & $8,42 \mathrm{Cb}$ & $9,45 \mathrm{Bb}$ & $10,48 \mathrm{Ab}$ \\
\hline 0,40 & $9,37 \mathrm{Ca}$ & $9,59 \mathrm{Ca}$ & $10,26 \mathrm{Ba}$ & $11,44 \mathrm{Aa}$ \\
\hline
\end{tabular}

Valores seguidos por letras distintas, maiúsculas na linha e minúsculas na coluna, diferem entre si pelo teste de $\mathrm{t}$ $(\mathrm{P}<0,05)$.

CNCPS: Cornel Net Carbohydrate and Protein System. 
Frações proteicas do capim-mombaça...

Tabela 4. Frações (\% MS) dos compostos nitrogenados do capim-mombaça (\%MS), obtidas pelo sistema CNCPS, durante o período seco

\begin{tabular}{|c|c|c|c|c|}
\hline \multirow[b]{2}{*}{ Altura (m) } & \multicolumn{4}{|c|}{ Doses de nitrogênio $\left(\mathrm{kg} \cdot \mathrm{ha}^{-1}\right)$} \\
\hline & 0 & 100 & 300 & 500 \\
\hline & & Fração A & & \\
\hline 0,20 & $40,62 \mathrm{Aa}$ & $38,99 \mathrm{Ba}$ & $37,62 \mathrm{Ca}$ & $38,67 \mathrm{Ba}$ \\
\hline 0,40 & $29,26 \mathrm{Db}$ & $38,96 \mathrm{Aa}$ & $35,91 \mathrm{Cb}$ & $37,89 \mathrm{Ba}$ \\
\hline & & Fração $B_{1}$ & & \\
\hline 0,20 & $1,84 \mathrm{Aa}$ & $1,69 \mathrm{Aa}$ & $2,21 \mathrm{Aa}$ & $1,94 \mathrm{Aa}$ \\
\hline 0,40 & 1,39Aa & $1,47 \mathrm{Aa}$ & $1,78 \mathrm{Aa}$ & $1,73 \mathrm{Aa}$ \\
\hline & & Fração $B_{2}$ & & \\
\hline 0,20 & $14,97 \mathrm{Bb}$ & $13,53 \mathrm{Ca}$ & $15,71 \mathrm{Ba}$ & $16,89 \mathrm{Ab}$ \\
\hline 0,40 & $19,33 \mathrm{Aa}$ & $12,11 \mathrm{Db}$ & $16,44 \mathrm{Ca}$ & $18,03 \mathrm{Ba}$ \\
\hline & & Fração $B_{3}$ & & \\
\hline 0,20 & $31,38 \mathrm{Bb}$ & $34,50 \mathrm{Ab}$ & $34,50 \mathrm{Ab}$ & $31,99 \mathrm{Ba}$ \\
\hline 0,40 & $40,06 \mathrm{Aa}$ & $37,46 \mathrm{Ba}$ & $35,87 \mathrm{Ca}$ & $32,56 \mathrm{Da}$ \\
\hline & & Fração C & & \\
\hline 0,20 & $11,17 \mathrm{Aa}$ & $11,27 \mathrm{Aa}$ & 9,94Aa & $10,48 \mathrm{Aa}$ \\
\hline 0,40 & $9,94 \mathrm{Ab}$ & $9,98 \mathrm{Ab}$ & $9,98 \mathrm{Aa}$ & $9,77 \mathrm{Aa}$ \\
\hline
\end{tabular}

Valores seguidos por letras distintas, maiúsculas na linha e minúsculas na coluna, diferem entre si pelo teste de $\mathrm{t}$ $(\mathrm{P}<0,05)$.

CNCPS: Cornel Net Carbohydrate and Protein System.

O NNP, em ambos os períodos, alcançou valores superiores na altura residual de $0,20 \mathrm{~m}$, exceto para as doses de 300 e $500 \mathrm{~kg} \mathrm{ha}^{-1} \mathrm{de} \mathrm{N}$ no período das águas. Tal fato pode ser atribuído à maior proporção de folhas em relação à de colmos presente nessa altura. Os maiores valores da fração A foram observados no período seco, com variações de 37,6 a 40,6\% para altura de corte de $0,20 \mathrm{~m}$, e de 29,3 e $39,0 \%$ para $0,40 \mathrm{~m}$. Os valores médios dessa fração no período das águas variaram de 26,5 a $35,2 \%$ para a altura residual de $0,20 \mathrm{~m}$, e de 28,7 a $35,2 \%$ para $0,40 \mathrm{~m}$. Balsalobre et al. (2003) observaram teores de NNP no capim-tânzania entre 18,2 e $28,8 \%$ da $\mathrm{PB}$, sendo o menor valor para o primeiro ciclo de pastejo e o maior para o último ciclo.

Os valores encontrados para a fração $B_{1}$ não diferiram $(\mathrm{P}>0,05)$ entre doses de $\mathrm{N}$ nas duas alturas, com exceção da dose de $0 \mathrm{~kg} \cdot \mathrm{ha}^{-1}$ de $\mathrm{N}$ a $0,20 \mathrm{~m}$ de altura no período chuvoso. Os valores médios observados foram 2,6 e 4,1\%. Resultados diferentes foram observados por Cabral et al. (2004), que determinaram teores de $\mathrm{B}_{1}+\mathrm{B}_{2}$ de 22,$4 ; 34,6 ; 44,0$ e $82,8 \%$ da PB para as silagens de capim-elefante, milho, feno de capim-Tifton85 e farelo de soja, respectivamente.

Pereira et al. (2000), para a fração $B_{1}$, encontraram valores semelhantes aos maiores teores médios deste experimento, em farelo de algodão, com média de $4,2 \%$, e teores de 8,9 e $6,8 \%$ para cana-de-açúcar e cama de frango, respectivamente. $\mathrm{Na}$ fração $\mathrm{B}_{2}$, não houve diferença $(\mathrm{P}>0,05)$ entre as doses de 0 e $100 \mathrm{~kg} \cdot \mathrm{ha}^{-1}$ de $\mathrm{N}$ de adubação e entre $300 \mathrm{e}$ $500 \mathrm{~kg} \cdot \mathrm{ha}^{-1}$ de $\mathrm{N}$ na altura de $0,20 \mathrm{~m}$, no período chuvoso, diferentemente do que ocorreu na altura de $0,40 \mathrm{~m}$ em ambos os períodos, em que se observou diferença entre todas as doses. Entretanto, Clipes et al. (2006), ao trabalharem com amostras de extrusas da pastagem de capimmombaça manejada com período de ocupação de três dias e período de descanso de 36 dias, relataram teores de 4,4 e $32,8 \%$ no primeiro dia de ocupação para as frações $B_{1}$ e $B_{2}$ dos compostos nitrogenados (PB), respectivamente, e teores de 8,2 e 33,3\% para o terceiro dia de ocupação, o que corrobora com os teores da fração $B_{1}$ determinadas na altura residual de 0,20m, durante o período chuvoso, nas maiores doses de $\mathrm{N}$ avaliadas; já os teores da fração $\mathrm{B}_{2}$ foram superiores aos determinados nessa pesquisa.

Quanto à interação entre doses versus alturas, houve variação nas doses de 100 e $300 \mathrm{~kg} \cdot \mathrm{ha}^{-1}$ de $\mathrm{N}$, com valores médios no período chuvoso de $20,5 \%(0,20 \mathrm{~m}) ; 24,7 \%(0,40 \mathrm{~m})$ e $17,5 \%(0,20 \mathrm{~m})$; $14,1 \% \quad(0,40 \mathrm{~m}), \quad$ respectivamente. Estes resultados assemelham-se aos de Balsalobre et al. (2003), que encontraram variação de 14,9 a 
$25,2 \%$ de PB no capim-tanzânia. Ribeiro et al. (2001), em experimento com feno de tifton, encontraram valores próximos da proteína insolúvel, com taxa de degradação intermediária $\left(\mathrm{B}_{2}\right)$, entre os fenos, com valores médios de 31,3 ; 30,$9 ; 30,4$ e $31,2 \%$ para as idades de rebrota de $28,35,42$ e 56 dias, respectivamente.

A fração $B_{3}$ apresentou variação de 41,7 a $32,2 \%$ na altura de $0,20 \mathrm{~m}$, e de 44,5 a $30,8 \%$ na altura de $0,40 \mathrm{~m}$, no período chuvoso, observando-se diferenças $(\mathrm{P}<0,05)$ entre dose de $\mathrm{N}$ e altura, exceto entre as doses de 0 e $300 \mathrm{~kg} \cdot \mathrm{ha}^{-1}$ de $\mathrm{N}$ na altura de $0,40 \mathrm{~m}$. Resultados semelhantes foram citados por Balsalobre et al. (2003), que observaram valores médios em torno de $40 \%$ da PB na fração $B_{3}$. Mello e Nörnberg (2004), ao fracionarem as proteínas de silagens de milho, sorgo e girassol, encontraram valores médios para a fração $\mathrm{B}_{3}$ em torno de 10,6; 9,2 e 17,5\%, respectivamente.

Os valores médios determinados para a fração $\mathrm{C}$ variaram de 8,4 a $10,5 \%$ no resíduo de $0,20 \mathrm{~m}$, e de 9,4 a $11,4 \%$ para $0,40 \mathrm{~m}$ no período chuvoso (Tab. 3); de 9,9 a $11,3 \%$ para $0,20 \mathrm{~m}$, e de 9,8 a $9,9 \%$ para $0,40 \mathrm{~m}$, no período seco (Tab. 4 ). Não houve diferença entre a dose de 0 e a de $100 \mathrm{~kg} \mathrm{ha}^{-1}$ de $\mathrm{N}$ nas duas alturas residuais $(\mathrm{P}>0,05)$. Nota-se que a fração $\mathrm{C}$ apresentou acréscimo linear nas alturas de corte, sendo maior na altura de $0,40 \mathrm{~m}$, provavelmente em decorrência da presença do nitrogênio ligado à lignina contida nos caules. Henriques et al. (2007) em experimento realizado com os capins setária, hemarthria, angola e acroceres adubados com doses de 0,100, 200, 300 e 400kg $\cdot \mathrm{ha}^{-1}$ de $\mathrm{N}$, na forma de sulfato de amônio, e colhidos aos $28,42,56$ e 70 dias de idade, observaram que os efeitos da adubação nitrogenada sobre os escores do fator 1 (frações B3 e C) foram pequenos e inconsistentes, demonstrando pouca influência da adubação nitrogenada sobre essas frações, cujo maior teor encontrado foi de 1,00 (\% MS) no capim-acroceres aos 42 dias.

\section{CONCLUSÕES}

A adubação nitrogenada realizada no terço final do período chuvoso promove incrementos nos teores médios de proteína bruta no período seco; as doses de nitrogênio influenciam nos valores das frações proteicas; o capim-mombaça apresenta baixa indigestibilidade nas duas alturas residuais avaliadas, visto que os teores da fração $\mathrm{C}$ encontram-se em torno de $10 \%$ da $\mathrm{PB}$; a altura de corte do capim-mombaça interfere na contribuição dos componentes estruturais da planta, exercendo grande influência sobre as frações da proteína.

\section{REFERÊNCIAS BIBLIOGRÁFICAS}

BALSALOBRE, M.A.A.; CORSI, M.; SANTOS, P.M. et al. Composição química e fracionamento do nitrogênio e dos carboidratos do capim-tanzânia irrigado sob três níveis de resíduo pós-pastejo. Rev. Bras. Zootec., v.32, p.519-528, 2003.

BRÂNCIO, P.A.; NASCIMENTO JUNIOR, D.; EUCLIDES, V.P.B. et al. Avaliação de Três Cultivares de Panicum maximum Jacq. sob Pastejo. Composição Química e Digestibilidade da Forragem. Rev. Bras. Zootec., v.31, p.16051613, 2002.

BRASIL. Ministério da Agricultura e Reforma Agrária. Secretaria Nacional de Irrigação, Departamento Nacional de Meteorologia. Normais Climatológicas: 1961-1990. Brasília, 1992. 84p.

BURLISON, A.J.; HODGSON, J.; ILLIUS, A.W. Sward canopy structure and the bite dimension and bite weight of grazing sheep. Grass Forage Sci., v.46, p.29-38, 1991.

CABRAL, L.S.; VALADARES FILHO, S.C.; JOANIS, T.Z. et al. Taxas de digestão das frações proteicas e de carboidratos para as silagens de milho e de capim-elefante, o feno de capim-Tifton-85 e o farelo de soja. Rev. Bras. de Zootec., v.33, p.1573-1580, 2004.

CÂNDIDO, M.J.D.; ALEXANDRINO, E.; GOMIDE, C.A.M. et al. Período de descanso, valor nutritivo e desempenho animal em pastagem de Panicum maximum cv. Mombaça sob lotação intermitente. Rev. Bras. Zootec., v.34, p.1459-1467, 2005.

CARNEVALLI, R.A. Dinâmica da rebrotação de pastos de capim-mombaça submetidos a regimes de desfolhação intermente. 2003. 136f. Tese (Doutorado) - Escola Superior de Agricultura "Luiz de Queiroz", Universidade de São Paulo, Piracicaba. 
CLIPES. R.C; SILVA, J.F.C.; E. DETMANN, E. et al. Composição químico-bromatológica da forragem durante o período de ocupação em pastagens de capim-elefante (Pennisetum purpureum, Schum) e capim-mombaça (Panicum maximum, Jacq) sob manejo rotacionado Arq. Bras. Med. Vet. Zootec., v.58, p.868-876, 2006.

HENRIQUES, L.T.; SILVA, J.F.C.; DETMANN, E. Frações dos compostos nitrogenados de quatro gramíneas tropicais em diferentes idades de corte e doses de adubação nitrogenada. Arq. Bras. Med. Vet. Zootec., v.59, p.740-748, 2007.

KRISHNAMOORTHY, U.C.; MUSCATO, T.V.; SNIFFEN, C.J. et al. Nitrogen fractions in selected feedstuffs. J. Dairy Sci., v.65, p.217$225,1982$.

LAVRES, J.J. Combinações de doses de nitrogênio e potássio para o capim-mombaça. 2001. 103f. Dissertação (Mestrado) - Escola Superior de Agricultura "Luiz de Queiroz", Universidade de São Paulo, Piracicaba.

LICITRA, G.; HERNANDEZ, T.M.; VAN SOEST, P.J. Standardization of procedures for nitrogen fractionation of ruminant feeds. Anim. Feed Sci. technol., v.57, p.347-358, 1996.

MELLO, R.; NÖRNBERG, J.L. Fracionamento dos carboidratos e proteínas de silagens de milho, sorgo e girassol. Cienc. Rural, v.34, p.1537-1542, 2004.

MONTEIRO, F.A. Nutrição mineral e adubação. In: SIMPÓSIO SOBRE MANEJO DA PASTAGEM, 12., 1995, Piracicaba. Anais... Piracicaba: Fundação Estudos Agrários Luiz de Queiroz, 1995. p.219-244
PEREIRA, E.S.; QUEIROZ, A.C.; PAULINO, M.F. et al. Determinação das frações proteicas e de carboidratos e taxas de degradação in vitro da cana-de-açúcar, da cama de frango e do farelo de algodão. Rev. Bras. Zootec., v.29, p.1887-1893, 2000.

RIBEIRO, K.G.; PEREIRA, O.G.; VALADARES FILHO, S.C. et al. Caracterização das frações que constituem as proteínas e os carboidratos, e respectivas taxas de digestão, do feno de capim-tifton 85 de diferentes idades de rebrota. Rev. Bras. Zootec., v.30, p.589-595, 2001.

RUGGIERO, J.A.; ROSA, B.; FREITAS, K.R. et al. Avaliação de lâminas de água e de doses de nitrogênio na composição bromatológica do capim-mombaça. Biosci. J., v.22, p.9-19, 2006.

SANTOS, P.M.; BALSALOBRE, M.A.A.; CORSI, M. Efeito da frequência de pastejo e da época do ano sobre a produção e a qualidade em Panicum maximum cvs. Tanzânia e Mombaça. Rev. Bras. Zootec., v.28, p.244-249, 1999.

SILVA, D.J.; QUEIROZ, A.C. Análise de alimentos - métodos químicos e biológicos. Viçosa: UFV, 2002. 239p.

SNIFFEN, C.J.; O'CONNOR, J.D.; VAN SOEST, P.J. et. al. A net carbohydrate and protein system for evaluating cattle diets: II. Carbohydrate and protein availability. J. Anim. Sci., v.70, p.3562-3577, 1992.

VAN SOEST, P.J. Nutritional ecology of the ruminant. 2.ed. Ithaca: Cornell University, 1994. 476p. 